\title{
Fuzzy Rule-Based Fault Location Technique for Thyristor-Controlled Series-Compensated Transmission Lines
}

A. Naresh Kumar ${ }^{1}$, M. Ramesha ${ }^{2}$, S. Jagadha ${ }^{3}$, Bharathi Gururaj ${ }^{4}$, M. Suresh Kumar $^{5}$, and Kommera Chaitanya ${ }^{6}$

${ }^{1}$ Department of Electrical and Electronics Engineering, Institute of Aeronautical Engineering, Hyderabad, India

${ }^{2}$ Department of Electrical, Electronics and Communication Engineering, GITAM (Deemed to be University), Bengaluru, India

${ }^{3}$ Department of Mathematics, Institute of Aeronautical Engineering, Hyderabad, India

${ }^{4}$ Department of Electronics and Communication Engineering, ACS College of Engineering, Bengaluru, India

${ }^{5}$ Department of Aerospace Engineering, Sandip University, Nashik, India

${ }^{6}$ Department of Electrical and Electronics Engineering, Chaitanya Bharathi Institute of Technology,

Proddatur, India

\begin{abstract}
Estimating the distance of a transmission line with a flexible alternating current transmission system including a thyristor-controlled series compensator is a challenging task. The distance estimation technique based on a fuzzy rule-based system (FRS) in a thyristor-controlled seriescompensated transmission line with multi-location faults is investigated in this study. The Haar wavelet current coefficients of the relaying bus are utilized as inputs to accomplish the distance estimation task. The FRS is illustrated through the Mamdani system in the LabVIEW software. The efficacy of the FRS is studied considering the effects of variation with respect to fault parameters. The main characteristic FRS is that it does not involve any two-end communication links because it employs relay terminal measurements only.
\end{abstract}

Keywords: Fuzzy rule-based system, Multi-location faults, Transmission lines

\section{Introduction}

Received: Jun. 17, 2021

Revised : Aug. 21, 2021

Accepted: Sep. 9, 2021

Correspondence to: A. Naresh Kumar (ankamnaresh29@gmail.com)

@The Korean Institute of Intelligent Systems

cc) This is an Open Access article distributed under the terms of the Creative Commons Attribution Non-Commercial License (http://creativecommons.org/licenses/by-nc/ 3.0/) which permits unrestricted noncommercial use, distribution, and reproduction in any medium, provided the original work is properly cited.
Flexible alternating current transmission system (FACTS) controllers are a family of power electronics-based controllers that have become increasingly popular in electrical power and transmission systems. Recently, FACTS controllers have been established as a feasible transmission choice to accomplish effective utility of rights of way and enhanced transmission capacity to meet growing electrical demand. Among the different FACTS controllers, the thyristor-controlled series-compensated transmission line (TCSCTL) is a promising option for transferring control power [1]. It offers various functionalities, such as enhanced damping of power oscillations, active power flow, transient stability, mitigating the sub-synchronous resonance issue, and limiting the short-circuit current. Nonetheless, the protection of TCSCTL is more difficult and complicated than the protection of an uncompensated transmission line because of voltage and current inversions, reaching, and ferroresonance problems. Moreover, 
there are problems with mho relay functionalities in such applications.

TCSCTL is now a main part of the FACTS device group, and it is widely identified as an economical and effective means of solving the issues related to long transmission lines, such as, voltage and transient stability issues and FACTS controllers based optimal power flow control, in deregulation of the electrical power market to reduce losses and improve congestion management in transmission systems. Therefore, it is crucial to identify the specific fault issue in a transmission line so that the FACTS device is leveraged fully.

\section{Related Research}

Numerous studies have addressed the distance estimation of shunt faults (single location faults) in TCSCTL applications. Some the significant research include neural network-based distance estimation [2]3], genetic algorithm tuned support vector machine and artificial intelligence based faulty classifications [4 5], fuzzy-based section identification [6], fault detection [7], and fault analysis [89] for TCSCTL. The majority of studies have been validated on shunt faults, while only a few have addressed the issues related to the multi-location (two-location) faults in TCSCTLs. The popular computational approaches used in the development of multi-location fault models include neural networks [10[11], fuzzy rule-based systems (FRS) [12 13] , and support vector machines [14]. Among these methods, FRS is proven to be the most suitable method, followed by support vector machines and neural network techniques.

The most recent fault distance methods based on FRS are reported in [15--18], which draw current from the relay terminal. FRS fault diagnosis for TCSCTLs is reported in studies [19-23]. However, this technique does not locate multi-location faults in TCSCTLs. Furthermore, the techniques mentioned in [19-23] require simplicity. Therefore, a suitable method needs to be investigated with a simple process; however, this is not provided in the abovementioned studies. As a result, our research focuses on the issue mentioned above utilizing FRS in the LabVIEW software. In this context, this study utilizes a concept based on the FRS, whose objectives are stated as follows:

1) The main purpose of FRS study is to boost error (\%).

2) The speed of FRS is very high.

3) The FRS has no significant impact on instants $(\Phi)$, resistances (R), multi-location faults, and distance in each phase (D1, D2, D3).
4) It directly utilizes the current information without performing communication links.

The remainder of this paper is as follows: Section 3 explains the TCSCTL, and technical inputs used for obtaining the distance of multi-location faults. Section 4 describes the FRS technique in detail. In Section 5, the experimental evaluation of FRS using various data samples to verify its performance is illustrated. Finally, the obtained result are summarized in Section 6.

\section{Studied System}

A schematic representation of the TCSCTL considered in this study is demonstrated in Figure 1. This line operates at $500 \mathrm{kV}$ voltage, $100 \mathrm{~km}$ length, and $60 \mathrm{~Hz}$ frequency. The TCSCTL consists of one capacitor that is used in the line for compensation. The capacitor is connected in parallel with an air gap arrangement, a metal oxide varistor (MOV) that protects it from overvoltage. Furthermore, it is also in parallel with the series connected inductor and anti-parallel thyristor combination. The 3-phase time-domain currents (IA, IB, and IC) are extracted from the relay terminal. B-1 is considered a relay terminal because here the behavior of the TCSCTL with respect to varying currents is studied, which is simulated using the MATLAB/Simulink software environment. Figure 2 shows a flow chart of the proposed framework.

When a fault occurs in two phases of TCSCTL at two distances simultaneously, is known as a multi-location fault. The TCSCTL is simulated for a simulation time of $200 \mathrm{~ms}$, and the waveform of the instantaneous currents during the multilocation fault situation, that is, the B fault at $58 \mathrm{~km}$ and $\mathrm{C}$ fault at $15 \mathrm{~km}$, are shown in Figure 3. Here, the 3rd level Haar wavelet transform is used for extracting features from currents obtained via the TCSCTL simulations. To estimate the multilocation fault distance, input signals are simulated according to various fault scenarios. Following feature extraction, a generally suitable computational scheme is adopted by the proposed technique to perform the distance estimation task regarding multi-location faults. The Haar wavelet transforms are the easiest wavelet transforms. The main benefits of the Haar wavelet transform are the investigation of signals with sudden transitions, that is, monitoring of tool failures in machines, and rapid computation. The Haar wavelet transforms can be expressed as

$$
\psi(t)= \begin{cases}+1, & 0 \leq t \leq 1 / 2 \\ -1, & 1 / 2 \leq t \leq 1 \\ 0, & \text { Otherwise }\end{cases}
$$




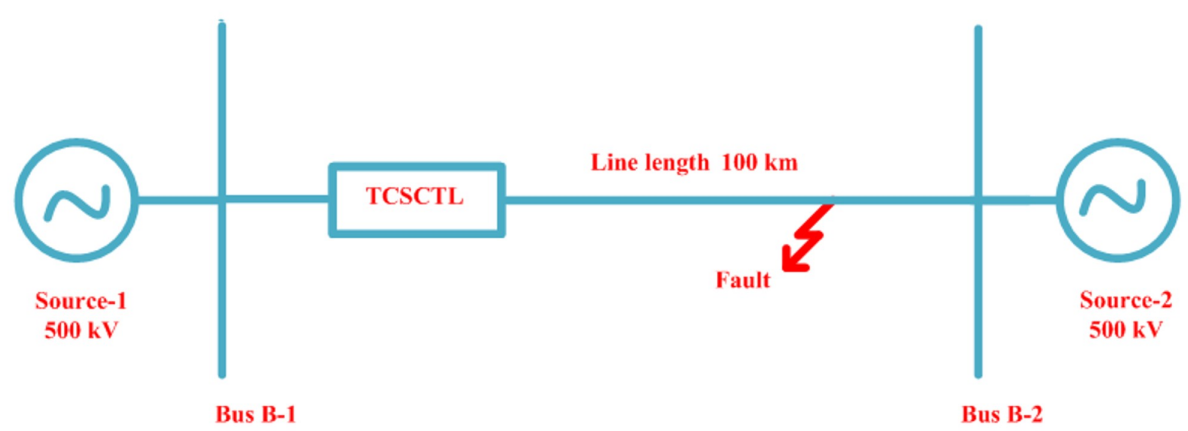

Bus B-1

Bus B-2

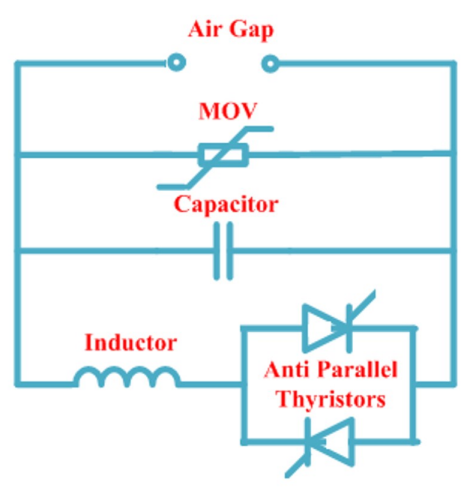

TCSCTL Component Connection

Figure 1. TCSCTL connection diagram.

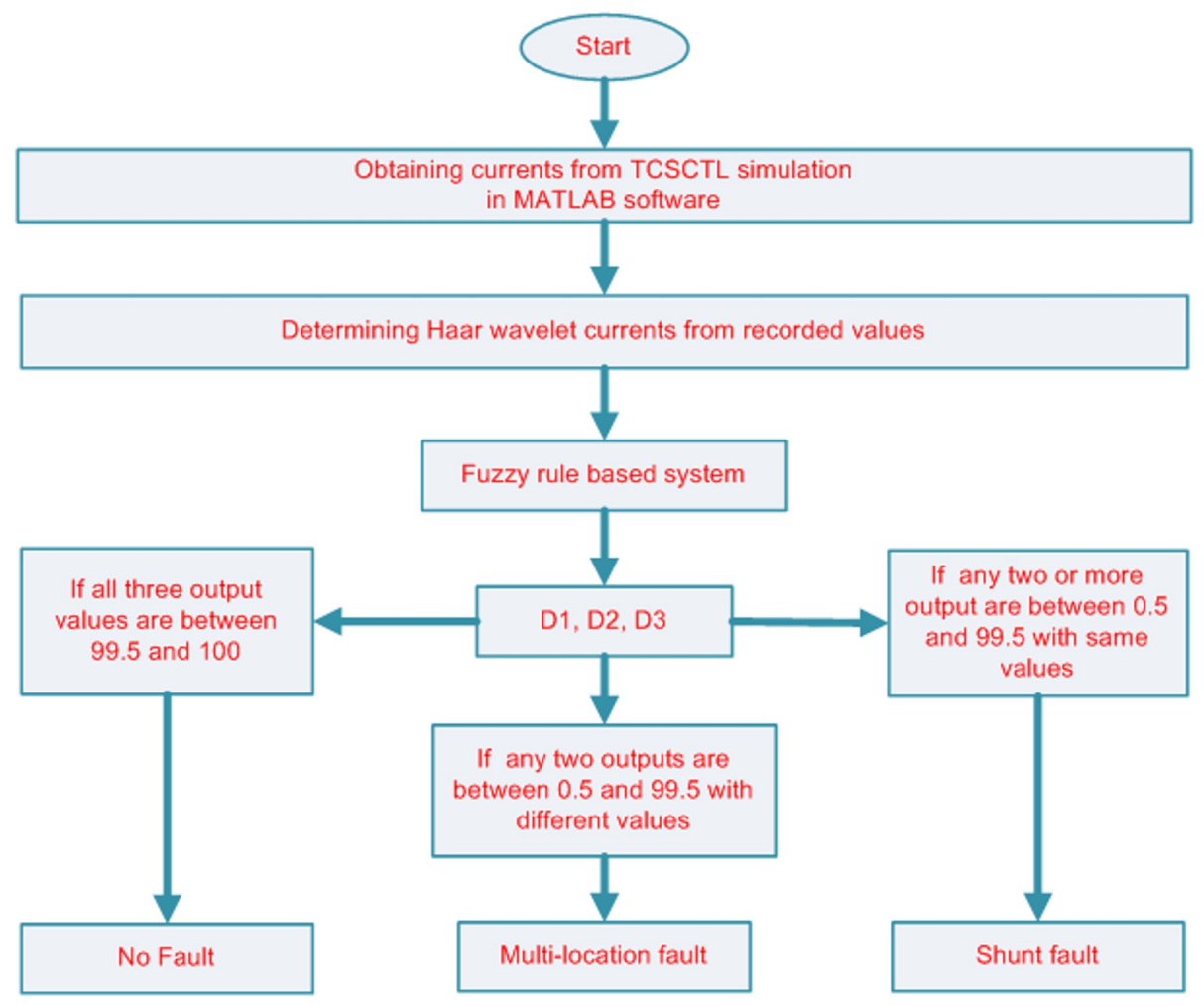

Figure 2. Flow chart of proposed FRS framework.

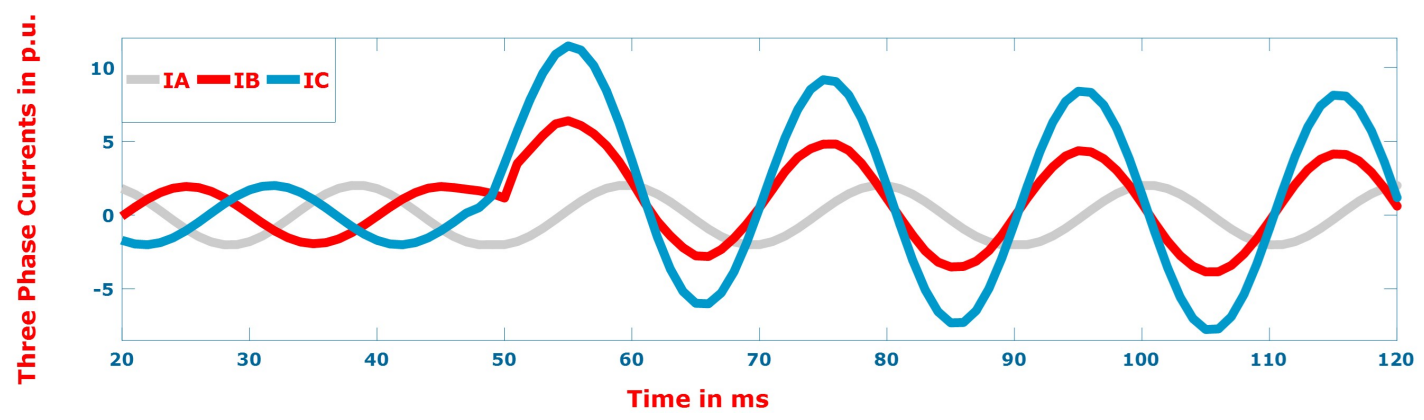

Figure 3. Current coefficients during multi-location fault. 


\section{Fuzzy Rule-Based System}

Fuzzy logic was introduced by Lofty Zadeh in 1965 based on the theory of "partial truth," that is the truth values lied between "absolutely false" and "absolutely true". Fuzzy logic provides a structure to design the uncertainty, perception process, and human way of reasoning. It is also based on natural language, and through a set of IF-THEN rules, an expert system is created, which is a function of fuzzy computations. Fuzzy logic has many benefits: first, it is applicable to many systems; furthermore, it can be understood simply owing to being mostly flexible; and finally, it can be used to design nonlinear functions of arbitrary complexities. The FRS components are depicted in Figure 4.

The FRS used in this study is of the Mamdani type. The input, outputs, and their membership functions are reported in Figure 5. The membership function is obtained by dividing the input and output gaps into separate parts in a triangular format. The IF-THEN rules have two components: an antecedent component and a consequent component. For each rule in the FRS, Haar wavelet currents are the antecedent of the rule, and the distance in each phase is the consequent. Each rule is then evaluated on these variables using the fuzzy AND operator to produce another value. The number of rules in the FRS scheme used here is 27, as shown in Figure 6. Each output parameter is a crisp value, which indicates the location in a range of $0-100$. Here, we used the most applicable method of defuzzification, the center of gravity method, to defuzzify the outputs.

\section{Experimental Results}

In this section, the adopted FRS scheme is examined on the widely studied $500 \mathrm{~V}, 60 \mathrm{~Hz}$, TCSCTL. The FRS scheme has been assessed with respect to different dynamic fault parame-

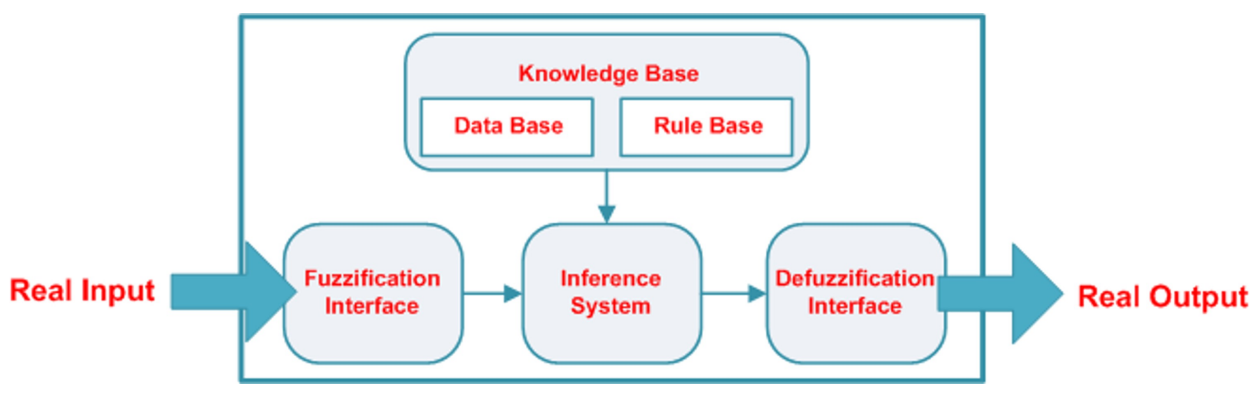

Figure 4. Fuzzy rule-based system.

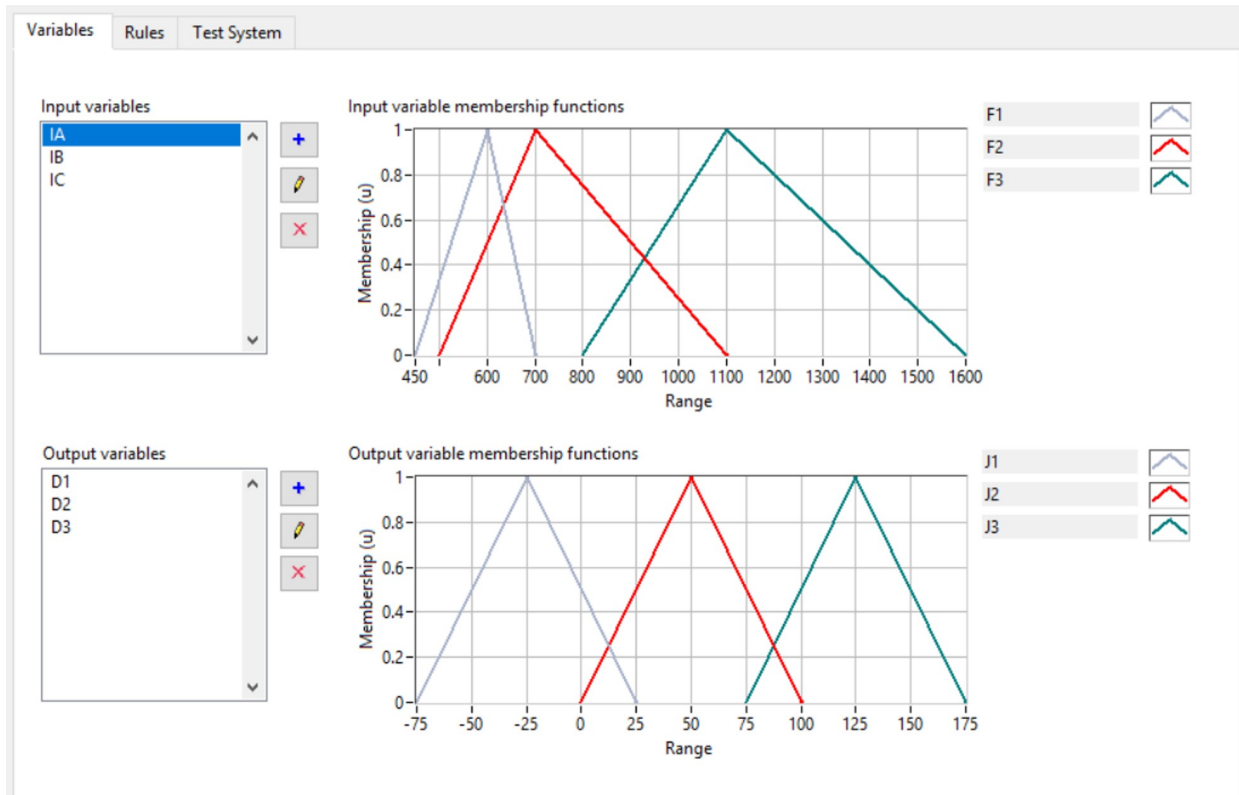

Figure 5. The input, outputs, and their membership functions. 


\section{FRS System IF-THEN Rules}

1. IF 'IA' IS 'F1' AND ' $B$ ' IS 'F1' AND 'IC' IS 'F1' THEN 'D1' IS 'J3 ALSO 'D 2 IS 'J3' ALSO 'D3' IS 'J3' 2. IF 'IA' IS 'F1' AND ' $B$ ' IS 'F1' AND 'IC' IS 'F2' T HEN 'D1' IS 'J3' ALSO 'D2 IS 'J3' ALSO 'D3' IS 'J2' 3. IF 'IA' IS 'F1' AND ' $B$ ' IS 'F1' AND 'IC' IS 'F3' T HEN 'D1' IS 'J3' ALSO 'D2 IS 'J3' ALSO 'D3' IS 'J1' 4. IF 'IA' IS 'Fl' AND ' $B$ ' IS 'F2' AND 'IC IS 'F1' THEN 'D1' IS 'J 3 ' ALSO 'D 2 IS 'J 7 ALSO 'D3' IS 'J3' 5. IF 'IA' IS 'F1' AND ' $B$ ' IS 'F2' AND 'TC' IS 'F2' T HEN 'D1' IS 'J3 ALSO 'D $y$ IS 'J $y$ ALSO 'D3' IS 'J2' 6. IF 'IA' IS 'F1' AND ' $B$ ' IS 'F2' AND 'TC' IS 'F3' THEN 'D1' IS 'J 3 ' ALSO 'D 2 IS 'J $y$ ALSO 'D3' IS 'J1' 7. IF 'IA' IS 'Fl' AND ' BB' IS 'F3' AND 'TC' IS 'F1' THEN 'D1' IS 'J3' ALSO 'D2 IS 'J1' ALSO 'D3' IS 'J3' 8. IF 'IA' IS 'F1' AND ' $\mathbb{B}$ ' IS 'F3' AND 'TC' IS 'F2' T HEN 'D1' IS 'J3' ALSO 'D 2 IS 'J1' ALSO 'D3' IS 'J2' 9. IF 'IA' IS 'F1' AND ' $B$ ' IS 'F3' AND 'TC' IS 'F3' T HEN 'D1' IS 'J3 ALSO 'D 2 IS 'J1' ALSO 'D3' IS 'J1' 10. IF 'IA' IS 'F2' AND ' $B$ ' IS 'F1' AND 'IC' IS 'F1' T HE N 'D1' IS 'J2' ALSO 'D 2 IS 'J3' ALSO 'D3' IS 'J3' 11. IF 'IA' IS 'F2' AND ' $B$ ' IS 'F1' AND 'IC' IS 'F2' T HE N 'D1' IS 'J2' ALSO 'D 2 IS 'J3' ALSO 'D3' IS 'J2 12. IF 'IA' IS 'F2' AND ' $B$ ' IS 'F1' AND 'TC' IS 'F3' T HE N 'D1' IS 'J2' ALSO 'D 2 IS 'J3' ALSO 'D3' IS 'J1' 13. IF 'IA' IS 'F2' AND ' $B$ ' IS 'F2' AND 'TC' IS 'F1' T HE N 'D1' IS 'J2' ALSO 'D2 IS 'J2' ALSO 'D3' IS 'J3' 14. IF 'IA' IS 'F2' AND ' $B$ ' IS ' $F 2$ ' AND 'TC' IS 'F2' T HE N 'D1' IS 'J2' ALSO 'D 2 IS 'J2' ALSO 'D3' IS 'J 15. IF 'IA' IS 'F2' AND ' $B$ ' IS 'F2' AND 'IC' IS 'F3' T HE N 'D1' IS 'J2' ALSO 'D 2 IS 'J2' ALSO 'D3' IS 'J1' 16. IF 'IA' IS 'F2' AND ' $B$ ' IS ' $F 3$ ' AND 'TC' IS 'F1' T HE N 'D1' IS 'J2' ALSO 'D 2 IS 'J1' ALSO 'D3' IS 'J3' 17. IF 'IA' IS 'F2' AND ' $B$ ' IS 'F3' AND 'IC' IS 'F2' T HE N 'D1' IS 'J2' ALSO 'D2 IS 'J1' ALSO 'D3' IS 'J2 18. IF 'IA' IS 'F2' AND ' $B$ ' IS ' $F 3$ ' AND 'IC' IS 'F3' T HE N 'D1' IS 'J2' ALSO 'D2 IS 'J1' ALSO 'D3' IS 'J1' 19. IF 'IA' IS 'F3' AND ' $B$ ' IS 'F1' AND 'IC' IS 'F1' T HE N 'D1' IS 'J1' ALSO 'D 2 IS 'J3' ALSO 'D3' IS 'J3' 20. IF 'IA' IS 'F3' AND ' $B$ ' IS 'F1' AND 'IC' IS 'F2' T HE N 'D1' IS 'J1' ALSO 'D 2 IS 'J3' ALSO 'D3' IS 'Jy 21. IF 'IA' IS 'F3' AND ' $B$ ' IS 'F1' AND 'IC' IS 'F3' T HE N 'D1' IS 'J1' ALSO 'D2 IS 'J3' ALSO 'D3' IS 'J1' 22. IF 'IA' IS 'F3' AND ' $B$ ' IS 'F2' AND 'IC' IS 'F1' T HE N 'D1' IS 'J1' ALSO 'D 2 IS 'J2' ALSO 'D3' IS 'J3' 23. IF 'IA' IS 'F3' AND ' $B$ ' IS 'F2' AND 'IC' IS 'F2' T HE N 'D1' IS 'J1' ALSO 'D 2 IS 'J2' ALSO 'D3' IS 'J2 24. IF 'IA' IS 'F3' AND ' $B$ ' IS ' $F 2$ ' AND 'TC' IS 'F3' T HE N 'D1' IS 'J1' ALSO 'D 2 IS 'J2' ALSO 'D3' IS 'J1' 25. IF 'IA' IS 'F3' AND ' $B$ ' IS 'F3' AND 'TC' IS 'F1' T HE N 'D1' IS 'J1' ALSO 'D 2 IS 'J1' ALSO 'D3' IS 'J3' 26. IF 'IA' IS 'F3' AND ' $B$ ' IS ' $F 3$ ' AND 'IC' IS 'F2' T HE N 'D1' IS 'J1' ALSO 'D 2 IS 'J1' ALSO 'D3' IS 'J 2 27. IF 'IA' IS 'F3' AND ' $B$ ' IS 'F3' AND 'IC' IS 'F3' T HE N 'D1' IS 'J1' ALSO 'D 2 IS 'J1' ALSO 'D3' IS 'J1'

Figure 6. IF-THEN rules.

ters, such as instants $(\Phi)$, resistances (R), multi-location faults, and distance in each phase (D1, D2, D3), where a total of 25,000 fault cases have been examined. The effects of varying $\mathrm{R}, \Phi$, shunt faults, distances, and types, and corresponding test results are reported in Tables 1-4. The FRS applications in multi-location and shunt faults in the LabVIEW fuzzy software are depicted in Figures 7 and 8, respectively. The error in the distance estimation of multi-location faults is calculated using Eq. (2).

$$
\text { Error }(\%)=\left|\begin{array}{c}
\begin{array}{c}
\text { Estimated fault location }(\mathrm{km}) \\
- \text { Real fault location }(\mathrm{km})
\end{array} \\
\text { Line length }
\end{array}\right| \times 100
$$

Table 1. Effect of varying $\phi$ in multi-location fault scenario (A fault at $11 \mathrm{~km}$ and $\mathrm{C}$ fault at $78 \mathrm{~km}$ )

\begin{tabular}{ccccccc}
\hline$\Phi$ & $\mathrm{R}$ & $\mathrm{D} 1$ & $\mathrm{D} 2$ & $\mathrm{D} 3$ & \multicolumn{2}{c}{ Error in phase } \\
\cline { 7 - 8 }$\left({ }^{\circ}\right)$ & $(\Omega)$ & $(\mathrm{km})$ & $(\mathrm{km})$ & $(\mathrm{km})$ & A fault & C fault \\
\hline 10 & 20 & 11.101 & 100 & 78.083 & 0.101 & 0.083 \\
50 & 20 & 10.880 & 100 & 78.155 & 0.220 & 0.155 \\
100 & 20 & 11.233 & 100 & 77.966 & 0.233 & 0.034 \\
150 & 20 & 11.147 & 100 & 77.801 & 0.147 & 0.199 \\
200 & 20 & 11.025 & 100 & 78.067 & 0.025 & 0.067 \\
250 & 20 & 10.735 & 100 & 78.221 & 0.265 & 0.221 \\
300 & 20 & 11.254 & 100 & 78.011 & 0.254 & 0.011 \\
350 & 20 & 11.211 & 100 & 78.226 & 0.211 & 0.226 \\
\hline
\end{tabular}

It is important to test the FRS application for close-in (1-5

$\mathrm{km})$ and remote-end $(95-99 \mathrm{~km})$ multi-location faults because 
Table 2. Effect of varying $\mathrm{R}$ in multi-location fault scenario (A fault at $92 \mathrm{~km}$ and $\mathrm{B}$ fault at $21 \mathrm{~km}$ )

\begin{tabular}{ccccccc}
\hline$\Phi$ & $\mathrm{R}$ & $\mathrm{D} 1$ & $\mathrm{D} 2$ & $\mathrm{D} 3$ & \multicolumn{2}{c}{ Error in phase } \\
\cline { 7 - 8 }$\left({ }^{\circ}\right)$ & $(\Omega)$ & $(\mathrm{km})$ & $(\mathrm{km})$ & $(\mathrm{km})$ & A fault & C fault \\
\hline 90 & 10 & 92.192 & 20.829 & 100 & 0.192 & 0.171 \\
90 & 30 & 92.034 & 21.186 & 100 & 0.034 & 0.186 \\
90 & 50 & 91.943 & 21.155 & 100 & 0.057 & 0.155 \\
90 & 70 & 92.091 & 21.245 & 100 & 0.091 & 0.245 \\
90 & 90 & 92.176 & 21.043 & 100 & 0.176 & 0.043 \\
90 & 110 & 91.803 & 21.024 & 100 & 0.197 & 0.024 \\
90 & 130 & 92.106 & 21.011 & 100 & 0.106 & 0.011 \\
90 & 150 & 92.131 & 21.162 & 100 & 0.131 & 0.162 \\
\hline
\end{tabular}

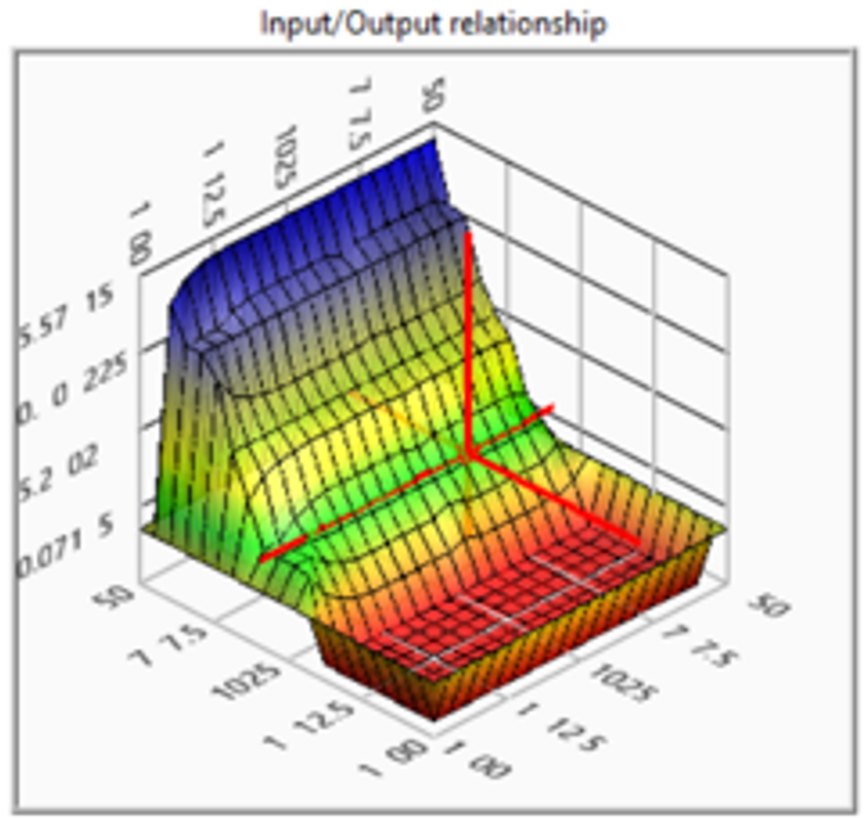

Figure 7. The outputs of FRS where phase B is located at $50 \mathrm{~km}$ at $46 \mathrm{~ms}$ and $\mathrm{C}$ is located at $14 \mathrm{~km}$ at $46 \mathrm{~ms}$, with the other output A located at $100 \mathrm{~km}$, indicating that there exists a $\mathrm{BC}$ multi-location fault.

in such cases the voltage and current magnitudes are different, which leads to relay failures. The results of the FRS for closein and remote-end multi-location faults are listed in Table 5. The FRS application during close-in and remote-end multilocation faults in the LabVIEW fuzzy software is shown in Figure 9. This confirms that the proposed scheme is not affected by the addition of close-in and remote-end multi-location faults. Moreover, observe that most fault cases are located below the 0.258 error value.

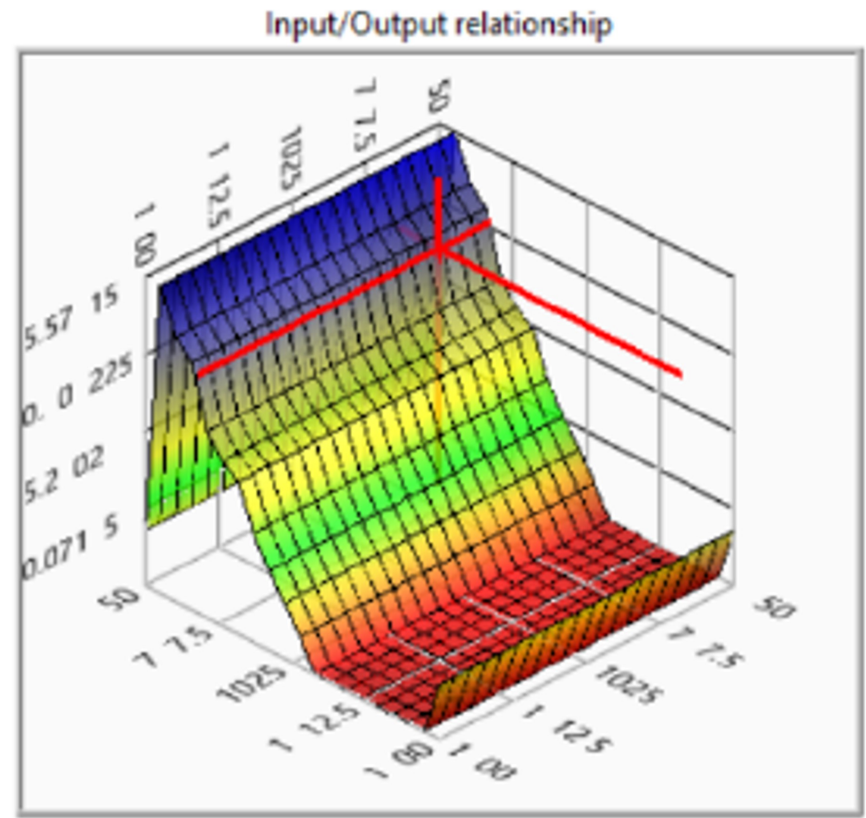

Figure 8. The outputs of FRS where phase $\mathrm{A}$ is located at $83 \mathrm{~km}$ at $46 \mathrm{~ms}$, with other outputs B and C located at $100 \mathrm{~km}$, indicating that there exists a BC-shunt fault.

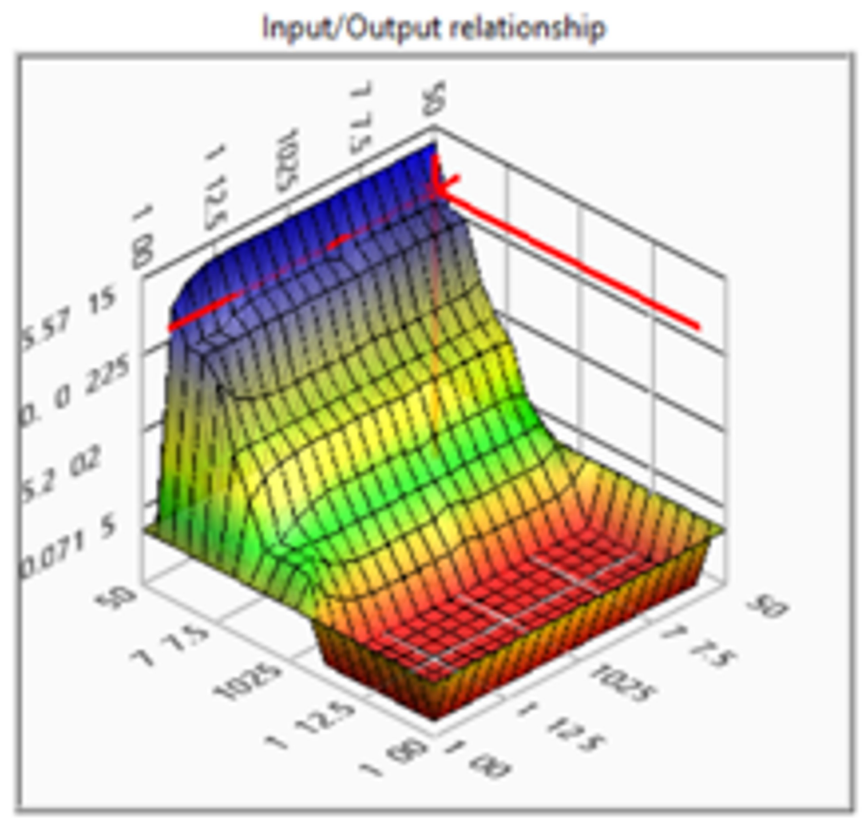

Figure 9. The outputs of FRS where phase A (close-in) is located at $3 \mathrm{~km}$ at $46 \mathrm{~ms}$ and C (remote-end) is located at $99 \mathrm{~km}$ at $46 \mathrm{~ms}$, with the other output B located at $100 \mathrm{~km}$, indicating that there exists an AC multi-location fault.

To assess the FRS performance, multi-location fault-based algorithms presented in $\left[\begin{array}{l|l|l|l|l|l|l|l|}3 & 12 & 14\end{array}\right]$ are chosen. The comparison results support the computational ones presented in Table 6 . The 
Table 3. Effect of varying distances and types

\begin{tabular}{|c|c|c|c|c|c|c|c|c|}
\hline$\Phi\left(^{\circ}\right)$ & $\mathrm{R}(\Omega)$ & Fault-1 & Fault-2 & $\mathrm{D} 1(\mathrm{~km})$ & $\mathrm{D} 2(\mathrm{~km})$ & D3 $(\mathrm{km})$ & $\begin{array}{l}\text { Error in } \\
\text { Fault-1 }\end{array}$ & $\begin{array}{l}\text { Error in } \\
\text { Fault-2 }\end{array}$ \\
\hline 45 & 75 & A-Phase fault at $28 \mathrm{~km}$ & B-Phase fault at $83 \mathrm{~km}$ & 28.134 & 83.252 & 100 & 0.134 & 0.252 \\
\hline 45 & 75 & A-Phase fault at $32 \mathrm{~km}$ & C-Phase fault at $67 \mathrm{~km}$ & 31.981 & 100 & 67.240 & 0.029 & 0.240 \\
\hline 45 & 75 & B-Phase fault at $44 \mathrm{~km}$ & C-Phase fault at $15 \mathrm{~km}$ & 100 & 43.864 & 15.066 & 0.136 & 0.066 \\
\hline 45 & 75 & A-Phase fault at $65 \mathrm{~km}$ & B-Phase fault at $26 \mathrm{~km}$ & 64.953 & 25.762 & 100 & 0.047 & 0.248 \\
\hline 45 & 75 & A-Phase fault at $18 \mathrm{~km}$ & C-Phase fault at $94 \mathrm{~km}$ & 18.213 & 100 & 94.125 & 0.213 & 0.125 \\
\hline 45 & 75 & B-Phase fault at $19 \mathrm{~km}$ & C-Phase fault at $06 \mathrm{~km}$ & 100 & 19.201 & 06.161 & 0.201 & 0.161 \\
\hline
\end{tabular}

Table 4. Effect of varying shunt faults

\begin{tabular}{cccccccc}
\hline$\Phi\left({ }^{\circ}\right)$ & $\mathrm{R}(\Omega)$ & Type & Distance $(\mathrm{km})$ & $\mathrm{D} 1(\mathrm{~km})$ & $\mathrm{D} 2(\mathrm{~km})$ & $\mathrm{D} 3(\mathrm{~km})$ & Error \\
\hline 180 & 50 & Phase-B fault & 9 & 100 & 8.926 & 100 & 0.074 \\
180 & 50 & Phase-B fault & 15 & 100 & 15.085 & 100 & 0.085 \\
180 & 50 & Phase-B fault & 28 & 100 & 27.068 & 100 & 0.068 \\
180 & 50 & Phase-B fault & 36 & 100 & 35.891 & 100 & 0.009 \\
180 & 50 & Phase-B fault & 44 & 100 & 44.104 & 100 & 0.104 \\
180 & 50 & Phase-B fault & 51 & 100 & 51.211 & 100 & 0.211 \\
180 & 50 & Phase-B fault & 60 & 100 & 60.282 & 100 & 0.282 \\
180 & 50 & Phase-B fault & 67 & 100 & 66.135 & 100 & 0.135 \\
180 & 50 & Phase-B fault & 73 & 100 & 72.823 & 100 & 0.177 \\
180 & 50 & Phase-B fault & 82 & 100 & 82.292 & 100 & 0.292 \\
180 & 50 & Phase-B fault & 89 & 100 & 89.124 & 100 & 0.124 \\
\hline 180 & 50 & Phase-B fault & 99 & 100 & 98.761 & 100 & 0.239 \\
\hline
\end{tabular}

Table 5. Effect of close-in and remote-end multi-location faults

\begin{tabular}{ccccccccc}
\hline$\Phi\left({ }^{\circ}\right)$ & $\mathrm{R}(\Omega)$ & Fault-1 & Fault-2 & D1 $(\mathrm{km})$ & $\mathrm{D} 2(\mathrm{~km})$ & $\mathrm{D} 3(\mathrm{~km})$ & $\begin{array}{c}\text { Error in } \\
\text { Fault-1 }\end{array}$ & $\begin{array}{c}\text { Error in } \\
\text { Fault-2 }\end{array}$ \\
\hline 45 & 75 & A-Phase fault at $1 \mathrm{~km}$ & B-Phase fault at $5 \mathrm{~km}$ & 1.163 & 99.189 & 100 & 0.163 & 0.189 \\
45 & 75 & A-Phase fault at 2 km & C-Phase fault at 4 km & 2.020 & 100 & 98.142 & 0.020 & 0.142 \\
45 & 75 & B-Phase fault at 3 km & C-Phase fault at 3 km & 100 & 3.863 & 97.067 & 0.137 & 0.067 \\
45 & 75 & A-Phase fault at 4 km & B-Phase fault at 2 km & 4.900 & 96.765 & 100 & 0.100 & 0.235 \\
45 & 75 & A-Phase fault at 5 km & C-Phase fault at 1 km & 5.244 & 100 & 95.088 & 0.244 & 0.088 \\
\hline
\end{tabular}

results of the FRS technique compared to those obtained by the algorithms presented in [310,12], achieve excellent distance estimation accuracy and track the output values well for all data sets. The FRS scheme designed in LabVIEW simulations outperforms the benchmark algorithms without planning complex techniques, such as those adopted in [3 10 | 10 |11 1 |14]. Therefore, we can conclude that more test samples are recommended than those used in [12 14]. To the best of our knowledge, no im- plementation has described the enhancement of multi-location fault distance estimation in TCSCTL, as we have in this study.

\section{Conclusion}

This study presented an FRS technique for the distance estimation of multi-location faults in TCSCTLs. In addition, the proposed research is independent of the Haar wavelet voltage and communication links. The standard deviation values of the 
Table 6. Comparison of FRS to established techniques

\begin{tabular}{|c|c|c|c|c|}
\hline Ref & Fault types & Model used & $\begin{array}{c}\text { Test } \\
\text { samples }\end{array}$ & Error \\
\hline [3] & $\begin{array}{l}\text { Multi-location } \\
\text { faults }\end{array}$ & $\begin{array}{c}\text { Neural } \\
\text { networks }\end{array}$ & - & 1 \\
\hline [10] & $\begin{array}{l}\text { Multi-location } \\
\text { faults }\end{array}$ & $\begin{array}{c}\text { Neural } \\
\text { networks }\end{array}$ & - & 1 \\
\hline [11] & $\begin{array}{l}\text { Cross-country } \\
\text { faults }\end{array}$ & $\begin{array}{c}\text { Neural } \\
\text { networks }\end{array}$ & - & 1 \\
\hline [12] & $\begin{array}{l}\text { Multi-location } \\
\text { faults }\end{array}$ & FRS & 1000 & 0.5 \\
\hline [13 & $\begin{array}{l}\text { Cross-country } \\
\text { faults }\end{array}$ & FRS & 20,000 & 0.41 \\
\hline [14] & $\begin{array}{l}\text { Cross-country } \\
\text { faults }\end{array}$ & $\begin{array}{l}\text { Support vector } \\
\text { machines }\end{array}$ & 14,500 & - \\
\hline [16 & $\begin{array}{l}\text { Simultaneous } \\
\text { faults }\end{array}$ & FRS & - & 0.4 \\
\hline $\begin{array}{l}\text { Proposed } \\
\text { FRS }\end{array}$ & $\begin{array}{l}\text { Multi-location } \\
\text { faults }\end{array}$ & FRS & 25000 & 0.25 \\
\hline
\end{tabular}

Haar wavelet current coefficients were considered for distance estimation of TCSCTL in multi-location faults. The drastic change in different faults provided significant results during the FRS validation. In addition, the FRS achieved high efficacy with respect to errors against line parameters. Furthermore, the enactment of the proposed FRS was compared to that of the other techniques. The proposed FRS scheme detected all types of multi-location faults with cycle time range between 0.01 to 0.46 seconds.

\section{Conflicts of Interest}

No potential conflicts of interest relevant to this article was reported.

\section{References}

[1] D. Jovcic and G. N. Pillai, "Analytical modeling of TCSC dynamics," IEEE Transactions on Power Delivery, vol. 20, no. 2, pp. 1097-1104, 2005. https://doi.org/10.1109/ TPWRD.2004.833904

[2] W. J. Cheong and R. K. Aggarwal, "Accurate fault location in high voltage transmission systems comprising an improved thyristor controlled series capacitor model using wavelet transforms and neural network," in Proceedings of IEEE/PES Transmission and Distribution Conference and Exhibition, Yokohama, Japan, 2002, pp. 840-845. https://doi.org/10.1109/TDC.2002.1177585

[3] A. Swetapadma and A. Yadav, "Improved fault location algorithm for multi-location faults, transforming faults and shunt faults in thyristor controlled series capacitor compensated transmission line," IET Generation, Transmission \& Distribution, vol. 9, no. 13, pp. 1597-1607, 2015. https://doi.org/10.1049/iet-gtd.2014.0981

[4] P. Tripathi, G. N. Pillai, and H. O. Gupta, "New method for fault classification in TCSC compensated transmission line using GA tuned SVM," in Proceedings of 2012 IEEE International Conference on Power System Technology (POWERCON), Auckland, New Zealand, 2002, pp. 1-6. https://doi.org/10.1109/PowerCon.2012.6401382

[5] B. Vyas, R. P. Maheshwari, and B. Das, "Investigation for improved artificial intelligence techniques for thyristorcontrolled series-compensated transmission line fault classification with discrete wavelet packet entropy measures," Electric Power Components and Systems, vol. 42, no. 6, pp. 554-566, 2014. https://doi.org/10.1080/15325008.2014. 880961

[6] P. Mazniewski and J. Izykowski, "Identification of faulted section in TCSC transmission line based on DC component measurement," in Proceedings of 2009 44th International Universities Power Engineering Conference (UPEC), Glasgow, UK, 2009, pp. 1-5.

[7] R. Nale and M. Biswal, "Fault detection algorithm for transmission line with Thyristor controlled series compensation," in Proceedings of 2016 International Conference on Control, Instrumentation, Communication and Computational Technologies (ICCICCT), Kumaracoil, India, 2016, pp. 457-460. https://doi.org/10.1109/ICCICCT. 2016.7987993

[8] B. Y. Vyas, R. P. Maheshwari, and B. Das, "Improved fault analysis technique for protection of Thyristor controlled series compensated transmission line," International Journal of Electrical Power \& Energy Systems, vol. 55, pp. 321-330, 2014. https://doi.org/10.1016/j.ijepes.2013.09. 015

[9] O. Cephas and A. Pandya, "Analysis of fault location in a transmission line with and without TCSC," Advances 
in Power Generation from Renewable Energy Sources (APGRES), Banswara, India, 2019.

[10] A. Swetapadma and A. Yadav, "An artificial neural network-based solution to locate the multilocation faults in double circuit series capacitor compensated transmission lines," International Transactions on Electrical Energy Systems, vol. 28, no. 4, article no. e2517, 2018. https://doi.org/10.1002/etep.2517

[11] A. Swetapadma and A. Yadav, "All shunt fault location including cross-country and evolving faults in transmission lines without fault type classification," Electric Power Systems Research, vol. 123, pp. 1-12, 2015. https://doi.org/10.1016/j.epsr.2015.01.014

[12] A. N. Kumar and M. Chakravarthy, "Fuzzy inference system based distance estimation approach for multi location and transforming phase to ground faults in six phase transmission line," International Journal of Computational Intelligence Systems, vol. 11, no. 1, pp. 757-769, 2018. https://doi.org/10.2991/ijcis.11.1.58

[13] A. N. Kumar, C. Sanjay, and M. Chakravarthy, "Fuzzy inference system-based solution to locate the cross-country faults in parallel transmission line," The International Journal of Electrical Engineering \& Education, vol. 58, no. 1, pp. 83-96, 2021. https://doi.org/10.1177\% 2F0020720919830905

[14] A. Swetapadma and A. Yadav, "Directional relaying using support vector machine for double circuit transmission lines including cross-country and inter-circuit faults," International Journal of Electrical Power \& Energy Systems, vol. 81, pp. 254-264, 2016. https://doi.org/10.1016/j.ijepes. 2016.02.034

[15] A. N. Kumar, C. Sanjay, and M. Chakravarthy, "Mamdani fuzzy expert system based directional relaying approach for six-phase transmission line," International Journal of Interactive Multimedia and Artificial Intelligence, vol. 6, no. 1, pp. 41-50, 2020. https://doi.org/10.9781/ijimai. 2019.06.002

[16] A. N. Kumar, C. Sanjay, and M. Chakravarthy, "Six phase transmission line protection against open conductor, phase to ground and simultaneous faults using fuzzy inference system," International Journal of Computational Intelligence Studies, vol. 8, no. 3, pp. 245-267, 2019. https://doi.org/10.1504/ijcistudies.2019.10024291
[17] A. Swetapadma and A. Yadav, "Fuzzy inference system approach for locating series, shunt, and simultaneous series-shunt faults in double circuit transmission lines," Computational Intelligence and Neuroscience, vol. 2015, article no. 79, 2015. https://doi.org/10.1155/2015/620360

[18] A. N. Kumar, C. Sanjay, and M. Chakravarthy, "A singleend directional relaying scheme for double-circuit transmission line using fuzzy expert system," Complex \& Intelligent Systems, vol. 6, pp. 335-346, 2020. https: //doi.org/10.1007/s40747-020-00131-w

[19] G. R. Rajeswary, G. R. Kumar, G. J. S. Lakshmi, and G. Anusha, "Fuzzy-wavelet based transmission line protection scheme in the presence of TCSC," in Proceedings of 2016 International Conference on Electrical, Electronics, and Optimization Techniques (ICEEOT), Chennai, India, 2016, pp. 4086-4091. https://doi.org/10.1109/ICEEOT. 2016.7755484

[20] R. Nale, H. Verma, and M. Biswal, "An enhanced fuzzy rule based protection scheme for TCSC compensated double circuit transmission system," International Journal of Modelling and Simulation, vol. 41, no. 2, pp. 120-130, 2021. https://doi.org/10.1080/02286203.2019.1692299

[21] M. Zand, M. A. Nasab, O. Neghabi, M. Khalili, and A. Goli, "Fault locating transmission lines with Thyristorcontrolled series capacitors by fuzzy logic method," in Proceedings of 2020 14th International Conference on Protection and Automation of Power Systems (IPAPS), Tehran, Iran, 2020, pp. 62-70. https://doi.org/10.1109/ IPAPS49326.2019.9069389

[22] S. M. Nobakhti and M. Akhbari, "A new algorithm for fault location in series compensated transmission lines with TCSC," International Journal of Electrical Power \& Energy Systems, vol. 57, pp. 79-89, 2014. https://doi.org/ 10.1016/j.ijepes.2013.11.052

[23] B. Kumar and A. Yadav, "A fuzzy logic system to detect and classify faults for laboratory prototype model of TCSC compensated transmission line," Journal of Power Technologies, vol. 99, no. 1, pp. 49-57, 2019. 


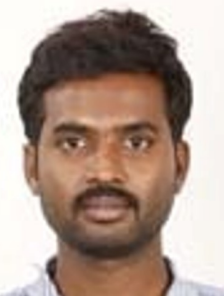

A. Naresh Kumar received the B.Tech. degree in Electrical and Electronics Engineering from Jawaharlal Nehru Technological University, Jagitiala, India in 2011. He received his M.Tech. degree in Electrical Engineering from National Institute of Technology, Raipur, India, in 2013. He completed his Ph.D. from department of Electrical and Electronics Engineering, GITAM University, Hyderabad. His areas of interest are power system protection, smart grid and soft computing applications. E-mail: ankamnaresh29@gmail.com

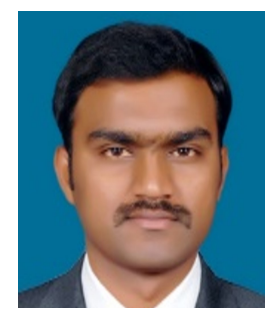

M. Ramesha received his Bachelor's degree from the VTU, Belagavi, and M.Tech. from Dayananda Sagar College of Engineering, Bangalore, and his Ph.D. degree from the GITAM University, Visakhapatnam. From January 2010 to June 2013, he was employed as Lecturer in YDIT, Bengaluru, and from June 2013 to July 2019, he worked as an Assistant Professor at ACS College of Engineering, Bengaluru. His research interests are in the area of the next-generation wireless communication system with special emphasis on various $5 \mathrm{G}$ technologies such as massive MIMO, mm-Wave, OFDM, FBMC, NOMA, and others. E-mail: ameshmalur037@gmail.com

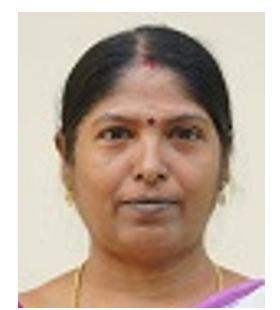

S. Jagadha received the B.Sc. degree in Mathematics from University of Madras, India in 1989. She received her M.Sc. degree in Mathematics from Osmania University, Hyderabad, India, in 2002. She completed her Ph.D. from department of Mathematics, Jawaharlal Nehru Technological University Anantapur.

E-mail: jagadhasaravanan@gmail.com

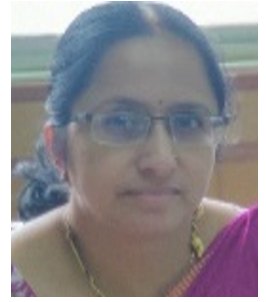

Bharathi Gururaj received her bachelor's degree from the PES Institute of Technology, Bangalore University, and M.Tech. from M S Ramaiah Institute of Technology, Bangalore, and Ph.D. degrees from the VTU, Belagavi. From July 2008 to June 2012, she was employed as Assistant Professor in SVCE, Bengaluru, and from July 2012 to Till date, she worked as an Assistant \& Associate Professor at ACS College of Engineering, Bengaluru. Her research interests are in the image \& video processing, wireless communication system. She has contributed more than 8 research journals.

E-mail: bharathigururaj@gmail.com

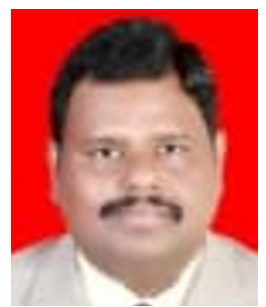

M. Suresh Kumar is holding 15 years experience, he is working as Prof. in the Dept. of Aerospace Engineering, Sandip University, Nashik. His research interests include: Electrical and Avionics. He has multiple publications to his credits.

E-mail: hodaerospace@sandipuniversity.edu.in

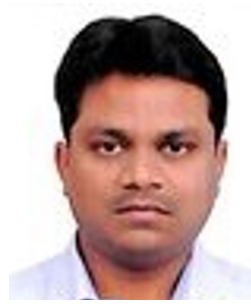

Kommera Chaitanya received the B.Tech. degree in electrical and electronics engineering from Vaagdevi Institute of Technology and Science, Proddatur, India in 2008. He received his M.Tech. degree in Electrical Engineering from Mahaveer institute of science and technology, Hyderabad, India, in 2011. His areas of interest are power system protection, smart grid and soft computing applications.

E-mail: chaitanya.k407@gmail.com 